\title{
Pelotas Is a Dead Museum: a fotografia e o design como ferramentas de exposição do abandono na cidade de Pelotas.
}

\author{
CERVANTES, Carolina Tanabe; Acadêmica do curso de Design Gráfico; Universidade Federal \\ de Pelotas \\ carolinatanabe@hotmail.com \\ MATHEUS, Pedro; Acadêmico do curso de Design Gráfico; Universidade Federal de Pelotas \\ pedro.m.theus@gmail.com \\ ULIANO, Marcelle de Lemos; Acadêmica do curso de Design Gráfico; Universidade Federal de \\ Pelotas \\ marcelle.uliano@hotmail.com \\ Orientadora: LIMA, Paula Garcia; Doutora em Memória Social e Patrimônio Cultural; Universi- \\ dade Federal de Pelotas. \\ paulaglima@gmail.com
}

Palavras-Chave: memória, patrimônio histórico e cultural, fotografia, Pelotas, abandono.

Resumo: Pelotas Is a Dead Museum consiste numa campanha fotográfica que objetiva expor o abandono de patrimônios históricos e culturais na cidade de Pelotas. Durante o desenvolvimento, utilizamos como base para leitura e interpretação de imagens um método proposto pela autora Martine Joly (2012). Os resultados alcançados foram um total de 13 peças gráficas com imagens obtidas durante 0 projeto, das quais uma delas é apresentada neste texto.

\section{Introdução}

O presente artigo refere-se a uma prática em grupo, feita para a disciplina de Fotografia do terceiro semestre do curso de design gráfico da Universidade Federal de Pelotas.

Para execução desta atividade, utilizou-se como tema o título Pelotas Is a Dead Museum (tradução: Pelotas é um Museu Morto). Produziu-se uma campanha fotográfica exibindo locais deteriorados e em estado de conservação ruim, nos quais se visualiza potencial e riqueza cultural a serem explorados, com o objetivo de chamar a atenção das pessoas para a existência desses "museus mortos" e para o fato de que esses espaços poderiam ser ocupados ao invés de estarem degradando-se entregues ao tempo. O nome originou-se de uma pichação que foi encontrada nas paredes do Instituto de Ciências Humanas (ICH) da UFPel antes da pintura do prédio no ano de 2015 , sendo que essa frase retrata com exatidão o objetivo do projeto.

\section{Metodologia}

Para o desenvolvimento do trabalho, realizaram-se pesquisas bibliográfica e documental, atreladas à prática da saída de campo, onde se visitou os locais abordados, fotografandoos. O projeto se resume em três etapas. Primeiramente, a pesquisa bibliográfica para fins de embasamento teórico. Nela, buscaram-se referências de autores que discorressem sobre imagem - escolheu-se a autora Martine Joly como referência em método para leitura de imagens. Então, deu-se a busca e a seleção por locais objeto através de sites locais, blogs, notícias e conversas informais com moradores e estudantes que alimentaram a coleta de dados sobre estes para o início da prática em campo. Por último, partiu-se para a etapa de

\section{UFPEL}


visitação para registro fotográfico. Utilizamou-se em toda a campanha um espelho quebrado como metáfora, com o objetivo de mostrar através do reflexo aquilo que estava ruindo diante dos olhos de todos sem ser notado. Com essas fotos criaram-se as peças gráficas do projeto, que consistem em um pôster, dois folders, dois cartões postais, dois marcadores de páginas e seis cartões de visita. Este texto traz, no entanto, apenas a leitura de uma das peças, um dos cartões de visita.

\section{Conhecendo os locais fotografados}

Como grupo, julgou-se necessário pesquisar os locais que seriam fotografados, primeiramente porque nenhum dos integrantes é pelotense, logo, precisou-se conhecer mais sobre a cidade. Ademais, para denunciar o abandono do patrimônio histórico cultural houve a necessidade de melhor conhecê-lo, o significado histórico de seus espaços e a gravidade do processo de abandono, justificando a necessidade de intervenção.

Um dos prédios eleitos foi a Antiga Sede do Banco do Brasil, localizada na Praça Coronel Pedro Osório, 67, esquina Praça Sete de Julho. De acordo com o texto "Cidade: Antigo prédio Banco do Brasil" (PREFEITURA DE PELOTAS), abrigou as atividades do banco durante 58 anos, recebendo investidores, pecuaristas, comerciantes e economistas. Em 1972 o prédio foi desapropriado para que a Câmara de Vereadores o ocupasse, o que não aconteceu, sendo instalada, então a Secretaria Municipal de Finanças. Sua arquitetura possui volumetria do ecletismo historicista e elementos compositivos ricos que chamam atenção, principalmente a cúpula, sacadas de púlpito, pilastras com capitéis coríntios e arabescos.

Outro local escolhido foi o Castelo Simões Lopes, construído em 1922 a mando do político Dr. Augusto Simões Lopes, neto do escritor Simões Lopes, localiza-se na Av. Brasil, 824, Fragata. Abrigou três gerações da família, sendo adquirido pela prefeitura de Pelotas em 1991, quando passou a sediar entidades culturais e por último foi sede de um centro psiquiátrico. Em 2004, o edifício sofreu um incêndio que danificou sua instalação elétrica e está em ruínas desde então. $O$ castelo conta com mais de trinta amplas peças e foi projetado por um arquiteto alemão. Existem promessas de revitalização do local, mas até então nunca foram cumpridas. Atualmente encontra-se sem nenhum tipo de segurança ou cuidado e extremamente depredado, mesmo se tratando de um patrimônio histórico tombado pelo estado do Rio Grande do Sul - Informações coletadas em "Castelo Simões Lopes está abandonado em Pelotas, RS" (JORNAL DO ALMOÇO).

Também se decidiu ir até a antiga Cervejaria da Brahma, atual Livraria da UFPel. Como mostra "As indústrias de Pelotas " (KREMER, 1992), no século XIX, na rua Benjamin Constant, 1071, localizava-se a Cervejaria Sul-Rio-Grandense. Anos mais tarde, a construção eclética foi comprada pela Brahma para servir como depósito e centro de distribuição e o que motivou a compra foi a busca pela eliminação da concorrência no comércio local. $O$ edifício permaneceu em ruínas por anos, até que foi adquirido pela Universidade Federal de

\section{UFPEL}




\section{SULDESIGN CIENTÍFICO 2017}

VIII Suldesign - encontro sul-americano

Pelotas e revitalizado para dar lugar à Livraria da UFPel, segundo o artigo "Bienal da UFPel consolidará antiga Brahma como espaço cultural para Pelotas” (UFPel, 2015).

Por último, a casa de 1900, uma edificação encontrada ocasionalmente quando este grupo ia rumo ao Castelo Simões Lopes. Localiza-se entre as ruas Uruguai e Manduca Rodrigues e chamou atenção por estar em um estado muito avançado de deterioração, com lixo e vegetação tomando conta do local, restando só a fachada e algumas paredes do que deveria ser uma casa de 116 anos.

\section{Resultados: peças gráficas finais e leitura das imagens}

Ao final desta campanha, vivenciou-se o abandono dos locais explorados e buscou-se exprimir a sua gravidade através das imagens selecionadas. Eis aqui uma imagem para realizar sua leitura segundo o método proposto por Joly:

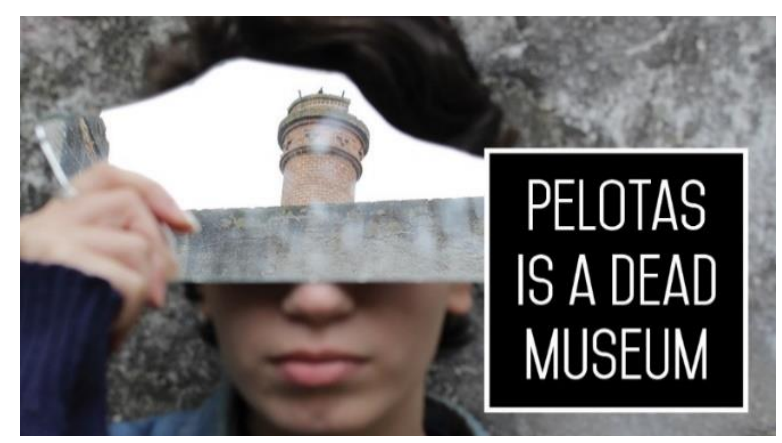

Figura 1: Frente de um dos cartões de visitas

Analisa-se o que se entende por significantes plásticos. O logotipo da campanha, junto da metáfora do espelho quebrado, presente em todas as peças, sinaliza que esta imagem corresponde a um conjunto e o espelho isoladamente trata, de maneira contínua, a questão do abandono, juntamente com o fundo surrado que integra aquela edificação. A presença da pessoa simboliza a população, o posicionamento do estilhaço do espelho tapando os olhos o desconhecimento em relação ao descuido, e o reflexo, o prédio em si. O enquadramento é estreito com a modelo posicionada à esquerda, o ângulo do ponto de vista é frontal, as cores estão entre de tons frios e de cinza, sendo a torre do reflexo uma única exceção de um tom um pouco mais quente. A iluminação utilizada foi natural e a imagem apresenta a textura das paredes surradas. A composição é sequencial e convida o olhar a percorrer o sentido de leitura da esquerda para a direita.

\section{Conclusão}

A partir deste projeto, concluí-se o quanto a imagem é um meio de comunicação impactante. Sua composição pode variar de acordo com as funções implícitas para cada uma, e, assim, trazer diversos significados a serem analisados, estes construindo-se a partir de experiências prévias de vida de cada indivíduo que influenciam na interpretação. Através da fotografia e do design, utilizando desses meios e elementos de composição, conseguiu-se alertar, vivenciar e enfatizar a questão do abandono.

\section{UFPEL}




\section{Referências}

PREFEITURA DE PELOTAS. Cidade: Antigo prédio Banco do Brasil. Disponível em:< http://www.pelotas.rs.gov.br/cidade atracoes/pelotas atracoes banco brasil.htm $>$. Acesso em 12 de out. 2016.

JORNAL DO ALMOÇO. Castelo Simões Lopes está abandonado em Pelotas, RS. Disponível em:<http://g1 .globo.com/rs/rio-grande-do-sul/jornal-do-almoco/videos/v/castelo-simoeslopes-esta-abandonado-em-pelotas-rs/3355665/. Acesso em 12 de out. 2016.

KREMER, A. As indústrias de Pelotas. Série do Jornal Diário da Manhã, Pelotas, set 1992.

UNIVERSIDADE FEDERAL DE PELOTAS, Coordenação de Comunicação Social. Bienal da UFPel consolidará a antiga Brahma como espaço cultural para Pelotas. Disponível em:<http://ccs2.ufpel.edu.br/wp/2015/10/08/bienal-da-ufpel-consolidara-a-antiga-brahmacomo-espaco-cultural-para-pelotas/>. Acesso em 12 de out. 2016.

J OLY, Martine. Introdução à Análise da Imagem. Editora Papirus, 2012. 